\title{
GERENCIAMENTO DO CUIDADO DE ENFERMAGEM COM LESÕES DE PELE NO CONTEXTO RURAL: PERCEPÇÕES DE ENFERMEIROS
}

\author{
MANAGEMENT OF SKIN LESIONS NURSING CARE IN THE RURAL CONTEXT: \\ PERCEPTIONS OF NURSES
}

\author{
Gímerson Erick Ferreira $^{\mathrm{a}^{*}}$, Patrícia Conferi Severo ${ }^{\mathrm{b}^{* *}}$, Samanta Andresa Richter ${ }^{\mathrm{c}^{* *}}$, \\ Edemilson Pichek dos Santos ${ }^{\mathrm{d}^{*}}$, Vilma Constância Fioravante dos Santos ${ }^{\mathrm{e}^{*}}$, \\ Êrica Rosalba Mallmann Duarte $\mathrm{f}^{\mathrm{f}^{*}}$ \\ agimersonferreira@faccat.br, bconferi.severo@hotmail.com, ${ }^{\mathrm{c}}$ samantarichter@sou.faccat.br, dedemilson@sou.faccat.br, \\ evilmasantos@faccat.br, 'ermduarte@gmail.com \\ *Faculdades Integradas de Taquara - Taquara (RS), Brasil \\ ** Universidade Federal do Rio Grande do Sul - Porto Alegre (RS), Brasil
}

Data de recebimento do artigo: 23/08/2017

Data de aceite do artigo: 19/09/2017

\section{RESUMO}

Introdução: A atenção primária à saúde (APS), eixo organizador e principal acesso dos usuários ao sistema de saúde, assume papel importante na proposiçáo e no desenvolvimento de açóes voltadas ao cuidado de pessoas com lesão de pele. O gerenciamento do cuidado voltado a essa especificidade é uma das responsabilidades do enfermeiro e, nesse sentido, é necessário que esse profissional esteja atento ao desenvolvimento e ao aperfeiçoamento de habilidades voltadas para o gerenciamento das açóes clínicas no cuidado prestado para que este seja efetivo. Objetivo: Conhecer as especificidades e configuraçóes para o gerenciamento do cuidado de enfermagem com lesóes de pele no contexto rural. Método: Estudo descritivo-exploratório, de natureza qualitativa, realizado com enfermeiros da APS de um distrito de saúde da área rural, localizado na regiáo metropolitana de Porto Alegre (RS). A coleta dos dados foi realizada através de entrevistas semiestruturadas, cujos resultados foram submetidos à análise de conteúdo temática. Resultados: Os dados coletados foram sistematizados em três categorias temáticas: especificidades da assistência à pessoa com lesão de pele no contexto rural; métodos de intervenção do enfermeiro no gerenciamento do cuidado; e configuraçôes para gestão de recursos no cuidado da pessoa com lesão de pele. Conclusóes: As particularidades do cuidado com lesôes de pele no contexto rural, a depender do modo como são gerenciadas, interferem na efetividade das açóes empreendidas, sendo necessário que o enfermeiro esteja atento ao estreitamento do vínculo com o paciente e desenvolva métodos de intervenção capazes de otimizar as práticas de gerenciamento de recursos com vistas à integralidade do cuidado.

Palavras-chave: Pele; saúde da população rural; atenção primária à saúde; gerenciamento da prática profissional; enfermagem.

\section{ABSTRACT}

Introduction: The primary health care (PHC), organizing axis and main access of users to the health system, plays an important role in the proposition and development of actions aimed at the care of people with skin lesions. The management of care focused on this specificity is one of the nurse's responsibilities, and in this sense it is necessary for this professional to be attentive to the development and improvement of skills aimed at the management of clinical actions in the care provided so that it is effective. Objective: To know the specificities and configurations for the management of skin lesions nursing care in the rural context. Method: A descriptive-exploratory study of a qualitative nature, carried out with nurses from the PHC of a rural health district, located in the metropolitan region of Porto Alegre (RS, Brazil). The data were collected through semi-structured interviews, whose results were submitted to thematic content analysis. Results: The collected data were systematized in three thematic categories: specificities 
of skin lesion assistance in the rural context; nurse's intervention methods in care management; and settings for resource management in the skin damage care. Conclusions: The particularities of skin lesions care in the rural context, depending on the way they are managed, do interfere in the effectiveness of actions undertaken, so it is necessary for the nurse to be attentive to the attachment tightening with patients, and to develop intervention methods able to optimize the resource management practices with a view to integral care.

Keywords: Skin; rural health; primary health care; professional practice management; nursing.

\section{Introdução}

No Brasil, o modelo de atenção à saúde voltado para as Estratégias de Saúde da Família (ESF) é uma proposta do Ministério da Saúde para reestruturar a atençấo primária com foco na família, inserida em seu ambiente, e voltado para as redes de apoio social que se constroem nos diferentes territórios. A atenção primária à saúde (APS) e as ESF são vistas como eixos organizadores e principais portas de entrada dos usuários para o sistema de saúde ${ }^{1}$, assumindo papel importante na proposição e no desenvolvimento de açóes voltadas ao cuidado de pessoas com lesão de pele. Os enfermeiros que atuam nesses espaços têm conquistado importantes avanços no reconhecimento do trabalho que desenvolvem e no campo científico, o que exige deles conhecimentos específicos e habilidades que não se restringem ao âmbito biológico ${ }^{2}$. $\mathrm{O}$ gerenciamento do cuidado voltado às pessoas com lesóes de pele é uma das responsabilidades do enfermeiro e, nesse sentido, é necessário que esse profissional esteja atento ao desenvolvimento e ao aperfeiçoamento de habilidades voltadas para o gerenciamento da clínica no cuidado prestado, para que este seja efetivo ${ }^{2,3}$.

A pele é um órgão essencial para a constituição e sobrevivência do ser humano por exercer funções importantes, como a proteçâo do meio externo. Também é o órgão utilizado para a estimulação do vínculo, através do contato pele a pele, que acaba despertando áreas do sistema nervoso ${ }^{4}$. Logo o gerenciamento do cuidado com lesóes de pele implica um olhar atento do enfermeiro para as especificidades do contexto de assistência, admitindo o cuidado como foco de suas açóes, as quais demandam articulação e engajamento de todos os atores envolvidos para sua efetividade.

Entretanto gerenciar o cuidado com lesóes de pele em contextos de atenção à saúde historicamente invisibilizados, em relação às políticas públicas e às particularidades que agregam maior complexidade ao cuidado oferecidos, como é o caso do contexto rural, ainda é um desafio. A criação de política pública específica e de serviços de saúde da atençáo primária para essa população ${ }^{1}$ deixa nítido que nem sempre há condições favoráveis para a efetividade das práticas assistenciais, constituindo-se um desafio para os enfermeiros, além de representar problemática relevante e pouco explorada no universo científico da enfermagem.
Ademais o contexto rural detém algumas especificidades, a exemplo do envelhecimento populacional, sendo que os idosos residentes nessas áreas, além de enfrentarem os problemas de saúde próprios da idade, acabam se defrontando com dificuldades para acessar os serviços de saúde em virtude do distanciamento geográfico, do acesso ao transporte e da renda ${ }^{6}$. Além disso, ressalta-se o distanciamento entre os profissionais da saúde que se inserem nesse contexto e os pacientes, pela via dos serviços de saúde e pelas especificidades locais que caracterizam esse espaço enquanto rural ${ }^{7}$.

Face ao exposto, presume-se que o gerenciamento do cuidado no contexto rural demande atuação proativa do enfermeiro no sentido de intervir preventivamente nas açóes de cuidado com os usuários acometidos por lesóes de pele, na perspectiva da integralidade. Quando o gerenciamento do cuidado é exercido de modo proativo pelo enfermeiro, pode culminar em repercussóes benéficas para os diferentes âmbitos em que o cuidado é desenvolvido ${ }^{2}$. Entretanto a experiência profissional dos pesquisadores tem demonstrado que nem sempre o cuidado da pessoa com lesão de pele é uma prioridade na agenda de serviços, o que pode sinalizar a necessidade de que isso seja visto com outro olhar, visando à produçẫo de práticas de enfermagem dermatológica com maior qualidade.

Assim, questiona-se: como os enfermeiros gerenciam o cuidado com lesões de pele em serviços de atenção básica do contexto rural? Quais as principais especificidades do contexto rural que são passíveis de gerenciamento? Que práticas de gerenciamento de recursos mostram-se relevantes no cuidado de enfermagem com lesóes de pele no contexto rural? Para buscar respostas a esses questionamentos, delineou-se um estudo com o objetivo de conhecer as especificidades e configuraçóes para o gerenciamento do cuidado de enfermagem com lesóes de pele no contexto rural da APS.

\section{Método}

Trata-se de uma pesquisa do tipo descritivo-exploratória, de natureza qualitativa, realizada no distrito rural de um município da região metropolitana de Porto Alegre, Rio Grande do Sul, Brasil. O distrito 
possui atualmente dez ESF, estruturadas em oito unidades de saúde. Nestas atuam 12 enfermeiros. O convite aos participantes deu-se através de ligação telefônica, e o agendamento para a coleta de dados foi feito de acordo com a disponibilidade para participar desta - apenas um profissional não se mostrou disponível para fazê-lo.

A coleta de dados foi realizada por meio de entrevistas semiestruturadas em seis ESF, com oito enfermeiros que atuam nesses serviços. Consideraramse como critérios de inclusão ser enfermeiro de ESF da área rural do município e trabalhar nesse cenário há pelo menos seis meses. Foram excluídos da composição amostral deste estudo os enfermeiros que no período de coleta de dados estavam afastados do serviço, ou que náo responderam ao convite de participação da pesquisa. Utilizou-se ainda o processo de amostragem por saturação, interrompendo-se a coleta de dados quando se constatou que não seriam mais depreendidos elementos novos para subsidiar a pesquisa nas circunstâncias apresentadas.

As entrevistas ocorreram no mês de outubro de 2016, após aprovação do projeto no Comitê de Ética em Pesquisa da Universidade Federal do Rio Grande do Sul, parecer número 1.673.204. O estudo, vinculado ao grupo de pesquisa Rede Internacional de Políticas e Práticas de Educação e Saúde Coletiva (Rede Interstício), contemplou as prerrogativas bioéticas, conforme Resoluçáo no 466, de 12 de dezembro de 2012, do Conselho Nacional de Saúde, sendo cadastrado na Plataforma Brasil sob o protocolo ${ }^{\circ}$ 56382316.2.3001.5338.

Os enfermeiros que aceitaram participar da pesquisa foram assegurados quanto ao caráter de livre participação no estudo e à preservação do anonimato na publicação dos resultados, expressando sua anuência por meio de assinatura em duas vias do Termo de Consentimento Livre e Esclarecido (TCLE), uma destinada ao pesquisador e outra ao participante. Por esse motivo suas opinióes serão representadas neste artigo por codificação, composta pela letra "E", de enfermeiro, seguida de um algarismo arábico sequencial.

Os dados foram analisados mediante análise de conteúdo do tipo temática ${ }^{8}$, norteada pelo objetivo do estudo. Inicialmente organizou-se o material de pesquisa, a partir de sua leitura exaustiva, assinalando, além dos sentidos apreendidos de todo o material, as unidades de significados relevantes à pesquisa. Em seguida, essas unidades de significados foram agregadas por similaridades e sistematizadas em três grandes categorias temáticas, as quais são apresentadas a seguir, nos resultados e na discussão deste estudo.

\section{Resultados e discussão}

Participaram da pesquisa sete enfermeiras e um enfermeiro, com idade variada (entre 25 e 42 anos), todos em estado civil casado. Os participantes possuem pós-graduação lato sensu, porém não necessariamente na área de atenção primária à saúde, sendo o tempo de formação destes em enfermagem variado - entre 1 e 15 anos de formação.

As especificidades e configuraçóes para o gerenciamento do cuidado de enfermagem com lesóes de pele no contexto rural, tema central do estudo no cenário investigado, podem ser apresentadas a partir da sistematização das três categorias temáticas estruturadas: especificidades da assistência à pessoa com lesão de pele no contexto rural; organização das práticas profissionais quanto ao cuidado com lesôes no contexto rural; e configuraçóes para gestâo de recursos no cuidado da pessoa com lesão de pele.

\section{Especificidades da assistência à pessoa com lesão de pele no contexto rural}

É necessário adaptar o planejamento do cuidado de enfermagem no contexto rural a algumas particularidades da sua populaçáo, considerando que a pessoa com lesão de pele apresenta um agravante nessas circunstâncias. Assim, aspectos relacionados à dificuldade de acesso, à adesão ao regime terapêutico, ao envelhecimento populacional e à inserção social foram núcleos de sentido encontrados como alicerces dessa categoria temática.

$\mathrm{O}$ acesso aos serviços de saúde interfere diretamente na adesão ao regime terapêutico, especialmente das pessoas acometidas por algum tipo de lesão de pele, as quais comumente apresentam limitaçôes físicas, o que dificulta ainda mais o acesso geográfico aos serviços ${ }^{7}$. Desse modo, as condições de saúde dos usuários são agravadas, culminando em incapacidades funcionais e interferindo na sua qualidade de vida por não terem atendimento de saúde 9 . As falas a seguir são ilustrativas dessa condição:

Para as pessoas que moram longe da unidade, dificulta. Porque em dias de chuva, nem ônibus entra em certos lugares, carro muito menos, então não tem como vir aqui... E nem todo paciente tem as condiçôes de vir à unidade! (EG)

na zona rural é tudo muito distante. Até para irmos lá ver, a gente depende de carro da prefeitura. E, então, se lá não tem um familiar que faça, também complica. Porque, às vezes, ele precisa vir aqui, ele não tem, não consegue vir todo dia... Então isso dificulta o tratamento! (E5) 
Além disso, as possibilidades de acessar os serviços de saúde, somadas ao modo como a pessoa é acolhida no primeiro atendimento da lesão de pele, podem definir a adesão ao tratamento e até mesmo a não utilização do serviço, especialmente por idosos de áreas rurais ${ }^{10}$. Assim, o enfermeiro precisa visualizar o usuário, para além do aspecto clínico da sua lesão, estabelecendo vínculo com ele e compreendendo-o em sua integralidade. Nesse sentido, precisa usar sua inteligência relacional e acessar as redes de serviços e de apoio desse usuário, no sentido de avaliar a disponibilidade deste e de seus familiares para realizar o curativo e a facilidade de utilização do recurso selecionado para seu acompanhamento terapêutico, sempre avaliando e reavaliando os fatores que podem interferir no tratamento.

Percebe-se, no que se refere à atenção a lesões de pele, que o enfermeiro assume o protagonismo nas açóes de cuidado, que é passível de gerenciamento, uma vez que as intervençóes de enfermagem, as quais requerem sistematização, mostram-se essenciais para a prevenção e o acompanhamento das alteraçóes cutâneas. Assim, o gerenciamento do cuidado nesse âmbito demanda a adoção de recursos estratégicos que possam atender às especificidades do contexto em que o usuário está inserido ${ }^{3}$.

Entretanto, no cenário investigado, percebeu-se que muitos usuários se tornam dependentes de seus cuidadores, familiares ou profissionais, o que pode estar relacionado a falhas no processo de educação para o autocuidado. Especialmente quando acometidos por lesôes de pele crônicas, uma vez que estas provocam alteraçóes de autoimagem, os indivíduos desenvolvem um processo de negação e resistência em relação a tais lesóes, evitando olhá-las, tocá-las e delas cuidar ${ }^{11}$. Assim, o enfermeiro precisa ser proativo ao articular os recursos necessários à construção de ações que favoreçam a autonomia do usuário, estabelecendo um plano de cuidados compartilhado e que desperte o indivíduo para o autocuidado.

O comprometimento da capacidade funcional provoca exclusão social, tendência ao sedentarismo, perda de autoestima, e isto, consequentemente, afeta a relação da pessoa com o próprio corpo, a autoestima e causa o afastamento da vida laborativa ${ }^{12}$.

não vêm com frequência, eles ficam dispersos, ele vem, às vezes faz um curativo, às vezes ele fica dias sem vir, então ele volta, mas já está com essa lesão piorada. Então geralmente nos casos das lesóes crônicas, das úlceras, os usuários já chegaram nesse estágio porque já não cuidaram muito, então eles já têm uma baixa adesão ao tratamento, ao cuidado. (E4)

Mas a gente tem todo esse estímulo que o familiar vai fazer o curativo, porque a gente não tem como se comprometer a, por exemplo: "Eu vou todo dia fazer curativo". Ou o paciente vem ou, senão, a gente ensina o familiar, porque não tem essa estrutura. Não existe isso, é impossivel. (E2)

Os entrevistados ressaltam dificuldades na adesão ao regime terapêutico proposto, salientando alguns fatores que interferem no processo de tratamento, principalmente a dependência elevada que as lesóes de pele podem causar. Essas singularidades despertam preocupação, haja vista que uma lesão cutânea geralmente demanda atendimento multidisciplinar e, desse modo, a continuidade no tratamento pode ficar comprometida se o cuidado não for gerenciado adequadamente. Entretanto a capacidade de resolução e de suporte da rede de atenção em saúde para a população rural ainda é deficitária, tendo em vista a desarticulação entre os serviços de atendimento ${ }^{7}$.

Outra particularidade que merece atenção é a desarticulação das redes de apoio social de que os idosos dispóem, a exemplo de suas famílias. De modo geral, assim como a população brasileira como um todo ${ }^{1}$, a porção rural tem uma quantidade de idosos considerável, e soma-se a isso o fato de que muitos deles moram sozinhos, além das distâncias geográficas que afastam as famílias dos espaços de cuidado formal em saúde ${ }^{7}$. Essa situação gera preocupaçóes e desamparo, bem como prejudica o trabalho cotidiano e até a atençáo com as questôes de saúde, não havendo, muitas vezes, um cuidador de referência ${ }^{6}$, fato que é agravado com as crises familiares e situaçóes de abandono, especialmente quando os sujeitos se encontram com lesões de pele crônicas ${ }^{12}$.

a população aqui é idosa, e muitos não sabem nem ler, nem escrever, e isso dificulta bastante, ou eles não têm mobilidade para fazer, então se é uma lesão no pé e ele é idoso, tem dificuldade para se abaixar. Então isso tudo dificulta para que ele melhore rápido. É um conjunto de coisas. (E5)

muitos pacientes idosos, com dificuldades de entendimento, moram sozinhos ou com outra pessoa idosa, aí não tem quem faça [...] então tu tens que orientar a fazer em casa [...] dai, as condiçóes em casa... Às vezes é só um casal de idosos. (E8)

É perceptível nos relatos acima que os idosos fazem parte da população que mais busca atendimento nos serviços de saúde, ou que mais demanda atençáo dos profissionais que desenvolvem suas atividades na APS. Em estudo sobre o envelhecimento no meio rural, foi evidenciado que os idosos inseridos nesse contexto, em sua maioria, fazem uso habitual dos serviços de saúde em função de condiçóes crônicas, como as lesôes de pele $^{10}$. Desse modo, os profissionais precisam ter a sensibilidade de disponibilizar um plano de cuidados que contemple as dificuldades das pessoas nessa faixa etária, considerando sua baixa escolaridade e dificuldade de 
entendimento, a mobilidade prejudicada para a prática do curativo e a distância das residências até a unidade de saúde.

Percebe-se nas falas que há pertinente inter-relação entre a população idosa e o baixo grau de instrução que esta apresenta, portanto a condiçáo social interfere no poder de enfrentamento dos problemas no cotidiano dos indivíduos. Nesse âmbito, salienta-se o trabalho dos enfermeiros como agentes propulsores das açóes interativas e integrativas na relação com os diferentes grupos da comunidade. E, no que tange ao meio rural, a capacidade de produzir cuidado em um sentido amplo, a habilidade de apreender e respeitar o outro imerso em signos que permeiam esse espaço, promovendo dignidade e direitos, e conviver com as diferenças culturais, assim como demanda o cuidado das lesóes de pele, são elementos imprescindíveis para uma atenção à saúde holística ${ }^{5}$. Assim, vislumbra-se os enfermeiros como articuladores do trabalho multiprofissional, uma vez que estes intervêm nas diversas dimensōes da saúde e do adoecimento dos indivíduos, da família e do grupo no contexto comunitário ${ }^{13}$.

ele não vem porque ele não tem dinheiro para pegar ônibus, porque ele tem que pegar ônibuspara vir à unidade, ou senão ele vem de carroça. Ou, às vezes, ele chega muito sujo... A gente tem que lavar primeiro, se é uma úlcera venosa [...], para depois iniciar o processo de curativo. [...] aqui eles não têm água encanada, é de poço, e muitas vezes não tem água na casa. Então éo poço escavado... Então, para tomar banho é de bacia, às vezes, ou então, pega na caixa d'água improvisada. (E8)

O relato apresentado mostra que as condiçóes sociais de habitação, saneamento e deslocamento ainda sâo especificidades do ambiente rural que interferem na qualidade do tratamento proposto, evidenciando a importância de uma política pública que permita atuar de forma intersetorial, no sentido de promover melhorias na qualidade de vida e de saúde da população rural, como na educação, no trabalho, no saneamento e no ambiente ${ }^{1}$. Esses elementos interferem diretamente no cuidado da pessoa com lesão, podendo prejudicar sua melhora, já que, em muitos casos, não há um cuidador ou outro membro da família coabitando com o indivíduo. Isso é particularmente preocupante, tendo em vista que a rede familiar é um dos sustentáculos da vida no meio rural. A família oferece apoio e cumpre uma função que embasa a organização social dos modos de viver e de construir o cotidiano das pessoas no enfrentamento dos problemas de saúde 5 .

Além disso, os enfermeiros ilustram a perspectiva de que, em função das especificidades até então apresentadas, a unidade de saúde é tida como referência na busca por serviços de saúde, principalmente devido à distância em que os indivíduos se encontram para acessar os serviços secundários e terciários. Nesse sentido, a procura pela unidade básica torna-se mais frequente, e o enfermeiro, ao agir de modo estratégico, encontra lócus favorável ao fortalecimento e ao estreitamento de vínculos com a comunidade.

eles vêm primeiro aqui, é o básico, é o primeiro atendimento, é a porta de entrada deles. Eles vêm sempre primeiro aqui no posto [unidade de saúde]. E às vezes quando eles têm que ir a outro lugar, eles ligam para cá, para pedir orientação pra gente. (E1)

O fortalecimento do vínculo também influencia na procura das ESF como referência primária no atendimento ao indivíduo com lesão de pele na área rural, pois na maioria das vezes seu histórico já é conhecido pela equipe, facilitando a resolução dos problemas de saúde, sem necessidade de ser referenciado para serviços urbanos ou de outros níveis de atenção, haja vista o difícil acesso e deslocamento geográfico. Além disso, o vínculo permite a construção de confiança, estimulando o autocuidado, favorecendo a compreensão da doença, a assimilação e o seguimento correto das orientaçôes terapêuticas pelos usuários ${ }^{14}$, assim como a pertinência da atençáo domiciliar ${ }^{8}$. Assim, é necessário que o enfermeiro se dê conta de que essa aproximaçáo traduz-se em fator estratégico para o efetivo gerenciamento do cuidado com lesóes de pele.

Eles geralmente trazem presentes: trazem aipim, trazem flor, trazem queijo [...] eles têm essa coisa bem de família. Tềm bastante vinculo, eu acho que o vínculo é bem maior do que nas unidades da cidade. (E5)

Se ele não veio, não culpá-lo, não fazer alguma coisa para que ele não volte mais. Se ele voltou, que bom, mas assim: "ah, vamos manter o acompanhamento, quem sabe o senhor...". A gente pensa outra estratégia e tal. Mas se, por exemplo: "ah, não veio mais, olha essa perna!". Não, a pessoa tem que se sentir acolhida, tem que sentir que a gente está do lado dela... A gente não sabe os motivos que fizeram a pessoa vir ou não, mas a gente tem que fazer com que ela volte sempre. (E2)

A retribuição de uma ação prestada pelo serviço de saúde por meio de presentes, como cita o entrevistado, é algo tratado com muita seriedade no âmbito rural, constituindo assim sua identidade e fortalecendo relações de confiança ${ }^{5}$. A geração de vínculo entre as pessoas com lesão de pele e os profissionais da equipe de saúde na área rural é diferenciada, conforme os relatos apresentados, pois os pacientes se revelam mais receptivos e conseguem estabelecer laços que se fortalecem pela frequência com que acessam a unidade e, em alguns casos, pela perda de sua inserção nas redes 
sociais em função da própria lesão ${ }^{12}$. A visualização dessa especificidade do contexto rural perpassa a adoção de estratégias proativas pelo enfermeiro no desenvolvimento de novas condutas, que possibilitem uma atuação fundamentada em preceitos da integralidade do cuidado.

\section{Organização das práticas profissionais quan- to ao cuidado com lesões no contexto rural}

Ao analisar as açóes dos enfermeiros no gerenciamento do cuidado em atenção à pessoa com lesão de pele em um contexto rural, o estudo possibilitou visualizar e discutir alguns métodos de intervenção empreendidos por estes profissionais para garantir que a assistência seja gerenciada. Esse gerenciamento acontece mediante articulação entre as dimensôes gerencial e assistencial presentes no trabalho do enfermeiro, expresso nas açóes de planejamento da assistência, de previsão e provisão de recursos, e de supervisão, liderança e capacitação da equipe de enfermagem ${ }^{15}$.

Neste estudo, essas ações são tomadas como métodos de intervençáa ${ }^{16}$, dos quais o enfermeiro se utiliza para gerenciar o cuidado de enfermagem: planejamento, tomada de decisão, supervisão e auditoria. A execução desses possibilita a prática de gerenciamento de recursos com vistas ao desenvolvimento de melhores práticas de cuidado do usuário com lesões de pele.

O planejamento da assistência de enfermagem como uma ação de gerência do cuidado se dá pelas escolhas exercidas durante a organização prévia das práticas. Compreende a avaliação das condições de saúde dos usuários e, desse modo, o direcionamento das açôes terapêuticas que serão realizadas, bem como a delegação de atividades para a equipe de enfermagem, a organização dos diferentes procedimentos aos quais os usuários são submetidos e a previsão/provisão dos materiais e recursos que são necessários ${ }^{14}$.

Às vezes a gente fica só "apagando incêndio", não consegue planejar nada [...] A gente tenta se organizar mais ou menos para que "a coisa ande", mas acho que falta tempo, realmente. Acho que essa é a maior dificuldade. (E3)

o responsável da área avalia, então prescreve a cobertura, orienta eles a fazerem o curativo e a periodicidade que a pessoa vai vir. Se tiver necessidade de iniciar antibiótico, que acontece na maioria das feridas crônicas, a gente inicia [...] ai a gente chama o médico para avaliar junto, o médico avalia, prescreve e a gente orienta o paciente a voltar. (E2)

As falas apresentadas mostram que o enfermeiro toma diversas decisóes em seu cotidiano de cuidado do usuário com lesões de pele. A frequência e a importância dessas decisōes variam em consequência de diferentes fatores, como local, responsabilidade individual, valores, entre outros, de modo que o enfermeiro em seu dia a dia de trabalho se depara constantemente com a necessidade de escolher a conduta mais apropriada para o cuidado do usuário.

Quando o paciente vem para fazer o curativo, o técnico nos avisa como que está a lesão, se está evoluindo positivamente, ou não, para a gente ver como atuar com a ferida. (E6)

Quando a gente vê que o paciente faz o curativo, a gente até cede o material e, às vezes, até coberturas, explica como tem que usar, porque a gente sabe da dificuldade de vir até a unidade [...]. Claro que se a gente vê que o paciente é tranquilo e vai fazer o curativo, a gente libera, senão, às vezes, a gente tenta ir atrás, tenta resgatar, mas se não tiver um interesse do paciente... O resultado não depende só da gente. (E3)

A supervisão tem sido historicamente desenvolvida pelo enfermeiro no cotidiano de trabalho na atenção primária, configurada por controle da produção, fiscalização e disciplinamento das ESF; porém não se resume a isso: deve ser vista como uma oportunidade de açôes de aprendizagem e acompanhamento da equipe e dos indivíduos. A supervisão dos agentes comunitários de saúde (ACS) é exercida pelo enfermeiro principalmente para controle dos processos de trabalho, contudo a finalidade da supervisão é centrada na qualificação da assistência prestada aos indivíduos da comunidade, como demonstra esta fala ${ }^{17}$.

Os próprios agentes trazem a demanda, mas nós mesmos, eu mesma dou uma cuidada, por exemplo, se vem um familiar renovar receita, eu digo: tá, mas essa senhora faz tempo que não vem, tem que vir... A próxima só em consulta. A gente dá uma reforçada: ah, ela não tem condiçóes de vir. Não, então, vamos marcar uma VD. [visita domiciliar]. (E5)

Os métodos de intervenção empreendidos pelos enfermeiros no gerenciamento do cuidado com lesóes expressam consonância com os preceitos de acolhimento, que é uma das principais diretrizes da Política Nacional de Humanização do Sistema Único de Saúde (SUS) no Brasil. $\mathrm{O}$ acolhimento elucida a recepção do usuário no serviço de saúde, compreendendo a responsabilização dos profissionais de saúde, a partir da escuta qualificada, da garantia de assistência resolutiva e da articulação com outros serviços para continuidade do cuidado, quando necessário $^{18}$. Tais preceitos remontam também à necessidade de controle dos processos, que devem se nortear por um fluxo que permita tecer as articulaçóes da rede de atenção e, posteriormente, a avaliação das açóes empreendidas.

Esse paciente, portador de ferida, passa pelo técnico e auxiliar de enfermagem. Então, dependendo, pelo enfermeiro 
e também pelo médico, porque tem alguns casos que eles precisam de uma prescrição médica, ou mesmo de um encaminhamento para um especialista, serviço de cirurgia. (E4)

Compreende-se que há a necessidade de avaliar os fluxos norteadores dos processos de trabalho no cuidado com lesóes de pele no contexto rural, pois essa prática possibilita repensar acerca do modo como o cuidado deve ser realizado, considerando as especificidades desse âmbito, tendo em vista as dificuldades de acesso e a necessidade de melhorias dos processos assistenciais dos serviços de atenção básica em saúde.

\section{Configurações para gestão de recursos na atenção à pessoa com lesão de pele}

A análise dos modos do gerenciamento dos recursos envolvidos no cuidado das pessoas com lesóes de pele e da sua disponibilidade são uma construção importante, haja vista o necessário provimento de recursos a fim de qualificar a prática clínica e assistencial das equipes, assim como garantir um direito dos usuários ${ }^{1}$. No cotidiano de trabalho do enfermeiro, esta prática está relacionada à aplicação dos métodos de intervenção na administração de recursos ${ }^{16}$.

No contexto rural, os enfermeiros destacam que a prática de recursos materiais é essencialmente importante para o gerenciamento do cuidado de lesóes cutâneas. Assim, as atribuições do enfermeiro nesse âmbito contemplam o planejamento, a tomada de decisão, a supervisão e a avaliação, com a finalidade de garantir a quantidade e a qualidade dos materiais necessários para que os profissionais realizem suas atividades sem riscos para si próprios e para os usuários, bem como para assegurar que haja uma prestação de cuidados adequados, com a utilização dos insumos devidos ${ }^{19}$.

Agora a gente ganhou, a gente consegue pegar pelo SUS, pelo pedido, sulfadiazina de prata, tem outros, o Dersani, tem as placas de hidrocolóide, tem outras coisas assim que estão melhor. (E5)

Agora a gente está com umas coberturas bem boas, o municipio pegou alginato [...] a gente só tinha vaselina líquida e soro. Então, agora tem alginato, hidrogel, hidrocoloide, tem várias coisas, Dersani, então está bem completo. Às vezes quando precisa de alguma coisa, colagenase, algum antibiótico junto, o médico ajuda, prescreve. (E3)

Os entrevistados demonstraram-se satisfeitos com a gestão pública pela aquisição de materiais especiais para a prática assistencial a lesóes de pele. Contudo somente a liberação de recursos materiais não é suficiente no contexto rural, sendo necessário que o enfermeiro que gerencia o cuidado com lesóes e prima pela qualidade da assistência de enfermagem busque capacitaçóes para usar coberturas com eficácia e eficiência, e esteja apto a gerenciar esses recursos, garantindo a responsabilidade no cuidado ${ }^{20}$.

No tocante aos recursos físicos, percebe-se nos relatos que os entrevistados se encontram insatisfeitos, alegando que os espaços físicos das unidades de saúde não têm a adequação de uma sala de curativos. Geralmente a prática de curativos é realizada no mesmo ambiente físico em que os demais procedimentos de enfermagem acontecem, expostos à observação de outros usuários e/ ou familiares, e não se dispóe de equipamentos adequados para que os serviços prestados sejam seguros, resolutivos e de boa qualidade.

eu vejo de dificuldade aqui no posto a estrutura física da unidade, por exemplo, a sala de curativo também é a sala onde a gente faz outros procedimentos. Ali se faz, por exemplo, medicação, se faz nebulização, se tem algum paciente que está grave, em observação, é ali que fica também. Então eu acho que se tivesse uma sala específica só para curativos, seria o ideal aqui no posto. (E1)

Então, como a gente está em reforma, não está realizando curativos, nossos pacientes que precisam de curativos estão sendo encaminhados para outras unidades próximas. (E4)

A maioria dos serviços investigados no contexto rural não possuem um local próprio e adequado para a prática de curativos, o que dificulta a organização do material necessário no momento de sua realização e aumenta o risco de contaminação. Além de não estar um ambiente seguro, a pessoa com lesão de pele pode ficar exposta, gerando algum constrangimento durante o procedimento.

Em se tratando de equipe profissional, os enfermeiros expóem que dispor de um quadro de recursos humanos que náo atua conforme a proposta de trabalho das ESF dificulta muito as ações, principalmente as práticas educativas do cuidado com lesóes. Além dessa dificuldade, um agravante ainda maior relacionado a tal situação é não dispor de um número ideal de profissionais na equipe de ESF rural, pois isso acarreta sobrecarga e, sobretudo, insatisfação e desmotivação com o trabalho ${ }^{19}$.

Primeiramente os técnicos de enfermagem, dependendo da situação, dependendo da lesão, já chama o enfermeiro para avaliar. É assim que a gente faz. [...] Então a atuação do enfermeiro é sempre avaliar quando o técnico chama, e as lesóes crônicas, geralmente a gente avalia sempre. (E8)

os curativos que eu acompanhei aqui que os familiares vinham junto, ajudavam, a gente orientava o familiar, of familiar ajudava a fazer o curativo. Então é importante, eu acho importante, sempre a presença do familiar. (E8) 
Percebe-se que açóes educativas voltadas à qualificação dos trabalhadores de enfermagem no meio rural são necessárias para o cuidado de pessoas acometidas por lesóes de pele, sendo preocupação do enfermeiro que gerencia o cuidado adotar um olhar propositivo, capaz de pensar em estratégias de ampliação da qualidade da assistência aos indivíduos e à coletividade, bem como a melhoria dos processos de prevenção e promoção da saúde. Nesse contexto, a participação do cuidador torna-se fundamental, pois auxilia no cuidado, complementando as ações prescritas e fortalecendo a continuidade do cuidado de enfermagem, especialmente para os usuários acamados e com limitaçóes de movimento que são atendidos no ambiente domiciliar ${ }^{20}$.

Por fim, com relação ao gerenciamento de recursos de informação, pode-se extrair dos relatos apresentados a necessidade de que os profissionais envolvidos no cuidado com lesôes de pele se norteiem por protocolos e diretrizes clínicas que possibilitem práticas assistenciais seguras, baseadas em evidências. Os enfermeiros do âmbito rural referem-se a uma capacitaçáo recente dos profissionais de enfermagem para utilização de coberturas especiais, mostrando-se mais satisfeitos e seguros por trabalhar em conformidade com um protocolo formalizado pela gestáo.

A gente tem o protocolo de enfermagem, até foi organizado pelo pessoal da secretaria, tá bem elaborado, eles prepararam com bastante resumo. Esse aqui é o do paciente com feridas, que é para a parte dos curativos. São listas de diagnósticos e intervençöes de enfermagem mais frequentes no atendimento a pacientes com feridas. Foi elaborado pelo pessoal da secretaria: queimadura, pé diabético, assim vai indo. No caso eles fizeram o resumo do resumo e isso auxilia bastante a gente na hora de fazer a avaliação. (E1)

A existência de protocolos assistenciais ou algoritmos, no sentido de sistematizar a assistência prestada, proporciona maior efetividade e eficiência na oferta de cuidados em atenção à pessoa com lesóes de pele ${ }^{3,12}$. Dessa forma, os enfermeiros do contexto rural entendem que a criaçáo de um protocolo se faz importante no gerenciamento de enfermagem, pois permite instrumentalizar as açóes dos profissionais e sistematizar a assistência a ser prestada à pessoa acometida por lesóes de pele, além de fornecer subsídios para a implementação desse tratamento. Também, em certa medida, pode facilitar o acesso dos usuários à rede de atenção em saúde, de forma mais organizada, tendo em vista que pode estabelecer fluxos de atendimento pelos serviços especializados quando necessário.

\section{Conclusão}

Dentro do contexto rural, algumas particularidades que norteiam o gerenciamento do cuidado de enfermagem com lesão de pele são percebidas pelos profissionais enfermeiros que atuam nesse cenário, tais como a acessibilidade prejudicada, o estabelecimento e estreitamento do vínculo com usuários e familiares, a prevalência da população idosa, a baixa adesão ao tratamento, entre outras.

A atuação do enfermeiro no gerenciamento do cuidado, no contexto rural, foi evidenciada por meio da aplicação de métodos de intervenção gerenciais que ressaltam a prática de administração de recursos indispensáveis ao cuidado integral em lesôes de pele.

Nesse sentido, os enfermeiros destacam as dificuldades de incorporar certas práticas de cuidado de lesóes cutâneas à rotina dos serviços das ESF em virtude dos percalços apresentados, sendo a localizaçáo do serviço um dos seus maiores entraves. Porém, mesmo com todas as adversidades específicas do contexto rural, os enfermeiros conseguem visualizar como recurso estratégico o fato de a unidade de saúde rural servir como referência para os usuários que habitam no respectivo território, o que favorece o desenvolvimento e o fortalecimento do vínculo entre profissionais e comunidade.

Para além dos aspectos curativos envolvidos no cuidado da pessoa que convive com lesóes de pele, é necessário que o enfermeiro, enquanto gerente de cuidados de enfermagem, fomente a continuidade de suas açóes com vistas à integralidade do cuidado. Os resultados favorecem a reflexão, a discussão e a crítica de enfermeiros sobre suas práticas assistenciais em lesōes cutâneas, contribuindo para a compreensão da importância do gerenciamento do cuidado nos serviços de saúde do meio rural.

Através deste estudo sugere-se a realização de novas pesquisas e o aprofundamento dos estudos existentes sobre pessoas com lesóes de pele no contexto rural, pois isso é de extrema importância para os usuários e para a enfermagem, no sentido de minimizar os agravos à saúde e proporcionar uma qualidade de vida melhor para essas pessoas.

\section{Referências}

1. Brasil. Ministério da Saúde: Política Nacional de Atenção Básica. Brasília, DF: Ministério da Saúde; 2012.

2. Ferreira GE, Rozendo CA, Santos RM, Pinto EA, Costa ACS, Porto AR. Características empreendedoras do futuro enfermeiro. Cogitare Enferm. 2013;18(4):688-94.

3. Pott FS, Ribas JD, Silva OBM, Souza TS, Danski MTR, Meier MJ. Algoritmo de prevenção e tratamento de úlcera por pressão. Cogitare Enferm. 2013;18(2):238-44.

4. Silva AK, Castoldi L, Kijner LC. A pele expressando o afeto: uma intervenção grupal com pacientes portadores de psicodermatoses. Contextos Clín. 2011;4(1):53-63. 
5. Ruiz FVR, Nai GA. Leucoplasia bucal - que lesão é esta? Colloq Vitae. 2016;8(2):37-45.

6. Bertuzzi D, Paskulin LGM, Morais EP. Arranjos e rede de apoio familiar de idosos que vivem em uma área rural. Texto Contexto Enferm. 2012;21(1):158-66.

7. Santos VCF, Gerhardt TE. A mediação em saúde: espaços e açôes de profissionais na rede de atenção à população rural. Saúde Soc. 2015;24(4):1164-79.

8. Minayo MCS. O desafio do conhecimento: pesquisa qualitativa em saúde. 14a ed. São Paulo: Hucitec; 2014.

9. Tavares DMS, Gávea Junior SA, Dias FA, Santos NMF, Oliveira PB. Qualidade de vida e capacidade funcional de idosos residentes na zona rural. Rev. Rene. 2011;12(n. esp.):895-903

10. Coêlho ADA, Lopes MVO, Melo RP, Castro ME. O idoso e a úlcera por pressão em serviço de atendimento domiciliar. Rev Rene. 2012;13(3):639-49.

11. Jesus PBR, Santos I, Brandão ES. A autoimagem e a autoestima das pessoas com transtornos de pele: uma revisão integrativa da literatura baseada no modelo de Callista Roy. Aquichan. 2015;15(1):75-89.

12. Joaquim FL, Camacho ACLF, Sabóia VM, Santos RC, Santos LSF, Nogueira GA. Impacto da visita domiciliar na capacidade funcional de pacientes com úlceras venosas. Rev Bras Enferm. 2016;69(3):468-77.

13. Sant'Anna CF, Cezar-Vaz MR, Cardoso LS, Erdmann AL, Soares JFS. Determinantes sociais de saúde: características da comunidade e trabalho das enfermeiras na saúde da família. Rev Gaúcha Enferm. 2010;31(1):92-9.
14. Santos JLG, Pestana AL, Guerrero P, Meirelles BSH, Erdmann AL. Práticas de enfermeiros na gerência do cuidado em enfermagem e saúde: revisão integrativa. Rev Bras Enferm. 2013;66(2):257-63.

15. Santos JLG, Lima MADS. Gerenciamento do cuidado: ações dos enfermeiros em um serviço hospitalar de emergência. Rev Gaúcha Enferm. 2011;32(4):695-702.

16. Sanna MC. A estrutura do conhecimento sobre administração em enfermagem. Rev Bras Enferm. 2007;60(3):336-8.

17. Silva JS, Fortuna CM, Pereira MJB, Matumoto S, Santana FR, Marciano FM, et al. Supervisão dos agentes comunitários de saúde na estratégia saúde da família: a ótica dos enfermeiros. Rev Esc Enferm USP. 2014;48(5):899-906.

18. Garuzi M, Achitti MC, Sato CA, Rocha SA, Spagnuolo RS. User embracement in the Family Health Strategy in Brazil: an integrative review. Rev Panam Salud Publica. 2014;35(2):144-9.

19. Roecker S, Budó MLD, Marcon SS. Trabalho educativo do enfermeiro na Estratégia Saúde da Família: dificuldades e perspectivas de mudanças. Rev Esc Enferm USP. 2012;46(3):641-9.

20. Mattos RM, Melo FBS, Araújo AKC, Gomes GMS, Vasconcelos LDS, Souza LDT. Educação em saúde aos trabalhadores de enfermagem e acompanhantes sobre prevenção e tratamento de lesóes de pele em dois hospitais de Petrolina-PE. Interfaces Rev Extensão UFMG. 2016;3(1):22-32.

\section{Como citar este artigo:}

Ferreira GE, Severo PC, Richter SA, Santos EP, Santos VCF, Duarte ERM. Gerenciamento do cuidado de enfermagem com lesóes de pele no contexto rural: percepções de enfermeiros. Rev. Aten. Saúde. 2018;16(55):5-13. 